\title{
Trend and factors associated with adverse birth weight in Uruguayan children between 2009 and 2015
}

Isabel Pereyra 1

(iD) https://orcid.org/0000-0002-4696-8063

Patricia Bustos 2

D https://orcid.org/0000-0001-8674-6142

1 Departmento de Nutrición. Universidad Católica del Uruguay. Av. 8 de Octubre 2738. Montevideo, Uruguay. E-mail: ipereyra@ucu.edu.uy
2 Departamento de Nutrición. Facultad de Medicina. Universidad de Chile. Santiago de Chile. Chile.

\begin{abstract}
Objectives: to identify trendand factors associated with adverse birth weight

Methods: cross-sectional design. The analysis uses the 2009-2015 Uruguay Perinatal Computer Systemdata on 303,625 newborns.

Results: the prevalence of macrosomia $(>3,999 \mathrm{~g}$ ) has increased from $7.0 \%$ to $8.4 \%$. The prevalence of low birth weight $(L B W)(<2,500 \mathrm{~g})$ decreased, standing at $6.6 \%$ in the last year. The factors that determines more possibilities of $L B W$ were preeclampsia $(O R=4.80$; $C I 95 \%=4.57-5.05)$, inadequate controls $(O R=2.29 ; C I 95 \%=2.20-2.39)$, shorter duration of pregnancy $(O R=2.52 ; C I 95 \%=2.50-2.55)$, previous hypertension $(O R=2.11 ; C I 95 \%=$ 1.96-2.27), hypertensive disease of pregnancy $(O R=1.82 ; C 195 \%=1.74-1.90)$, low prematernal maternal weight $(O R=1.65 ; C 195 \%=1.58-1.74)$. Macrosomia was associated with type 1 diabetes $(O R=2.21 ; C I 95 \%=1.86-2.61)$, Type 2 or Gestational $(O R=1.78 ; C 195 \%=$ 1.70-1.87), obesity maternal $(O R=2.33 ; C 195 \%=2.24-2.43)$ and longer gestation duration $(O R=2.62 ; C I 95 \%=2.53-2.72)$.

Conclusions: the $L B W$ decreases while the macrosomia increases. The health and nutritional status of women at the beginning of pregnancy, pathologies of the last trimester, smoking, shorter duration of pregnancy and inadequate controls are associated with BPN. Overweight, obesity and metabolic diseases determine macrosomia.
\end{abstract}

Key words Birth weight, Pregnancy, Uruguay

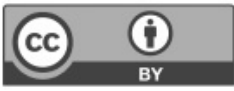




\section{Introduction}

Insofar as the right to health is an inclusive condition and is based on the principle of health as a citizen's right and duty of the state is not limited to health care, it also includes taking into account the determining factors that contribute to people's live healthy life. ${ }^{1}$ The size of the newborn determines the health and proper growth and development of children in the first months of life, for this reason it is considered as a variable of importance and permanent study as a marker of the health status in countries. $^{2}$

The World Health Organization (WHO) defines low birth weight (LBW) as the weight of the newborn below $2,500 \mathrm{~g}$, regardless of gestational age. 3 The reported prevalence of LBW for Latin America is on average $9 \%$, ranging from $6 \%$ to $12 \%$. In the countries of the Southern Cone (Argentina, Chile, and Uruguay), the prevalence is $7 \%, 6 \%$, and $8 \% .2,4$ Its importance goes beyond the first few months as has been known the correlation between LBW and increased rate of noncommunicable diseases during adult life (cardiovascular, diabetes). 5 Moreover, individuals with LBW and malnutrition in postnatal life have been shown to have an increased risk of cardiovascular mortality in adult life. 6,7

Macrosomia is defined as an infant's birth weight of more than 4,000 $\mathrm{g}$ regardless of gestational age and is the result of excess intrauterine growth. Macrosomia prevalence data are scarce in developing countries. In developed countries, the prevalence is between 5 and $20 \%$ and in recent decades there has been an increase of 15 to $25 \%$ due to the increase in obesity and maternal diabetes. ${ }^{8}$ The neighboring countries of the Southern Cone have 7\% and $9 \%$ macrosomia (Argentina and Chile respectively). ${ }^{8}$ It is associated with childbirth with complications and an increased risk of overweight or obesity in childhood, adolescence, and adult life and numerous noncommunicable diseases which have been an ever-frequent occurrence recently. 9,10

The nutritional situation at birth (evidenced by weight) is conditioned on multiple factors that change over the years. Epidemiological studies on the gestation, birth, and health of newborns contribute to providing quality data to analyze the causes of mortality, hospitalization, survival-related factors, inequity and provide possible solutions to the health problems of pregnant women and the offspring.2,11

For many years, birth rates have remained constant in Uruguay (13.4/1000 inhabitants as of
2012), nutritional deficit problems have decreased, and access to health care has improved, and excess weight during pregnancy has increased. ${ }^{12}$ Working with national database data to associate maternal variables with child morbidity is of central importance. The Ministry of Health of Uruguay defined the National Strategic Goals 2015-2020 and among these: decreased mortality and child morbidity, reduction of the prevalence of stunting, and decreased overweight and obesity in the population.

There are, however, no published studies of national data on the determinants of low-weight and macrosomia rates, which constitutes two situations of vulnerability to health problems. The objective of the study was to identify the trendand factors associated with adverse birth weight in Uruguay.

\section{Methods}

This study has a cross-sectional design. The study population consisted of infants born in Uruguay from 1 January 2009 to 31 December 2015. The data belongs to the vital statistics registered in the Uruguay- Perinatal Information System (SIP, the Spanish-language acronym) that are collected annually by law. Monthly, each health institution forwards the data of all births to the Ministry of Public Health in digital format, according to its regulations it is mandatory to refer $100 \%$ of births, being the institutional technical management responsible for the proper use of the SIP. 12

For the analysis, we first identified missing and outliers data for birth weight (less than $800 \mathrm{~g}$ and greater than 5,500g) in the universe of birth $(311,385)$, exclusion criteria were twin newborns, duration of pregnancy less than 22 weeks and higher than 42 weeks. The final number of participants was 303,625 .

To analyze the adverse birth weight, the weight at birth in grams was operationalized as a categorical variable indicating: low weight $(<2,500 \mathrm{~g})$, normal weight $(2,500 \mathrm{~g}-3,999 \mathrm{~g})$ and macrosomia $(\geq 4,000 \mathrm{~g}) .3,9$

The exposition variables considered for their relationship with birth weight was: gestational duration, pathologies, substance use, pregnancy medical care, pre-gestational nutritional status of the woman and sex of the offspring.

Gestational age was linked to the health certificate records at birth instead of using the date of last menstruation because the latter overestimates the weight higher than or equal to $2,500 \mathrm{~g}$ in preterm birth, considering lower gestational age. 13

Maternal pre-gestational nutritional status of the 
woman was operationalized with the body mass index (BMI) before pregnancy [weight $(\mathrm{kg}) /$ height (m) ${ }^{2}$, which was categorized into four groups: low weight $\left(<18.5 \mathrm{~kg} / \mathrm{m}^{2}\right)$, normal weight $(18.5-24.9$ $\left.\mathrm{kg} / \mathrm{m}^{2}\right)$, overweight $\left(25.0-29.9 \mathrm{~kg} / \mathrm{m}^{2}\right)$ and obesity $\left(\geq 30.0 \mathrm{~kg} / \mathrm{m}^{2}\right) .14$

Pregnancy controls were classified as adequate, intermediate, and inadequate, using a measure of the required number of visits according to the weeks of gestation, where the higher gestational age requires a higher number of prenatal care visits. This technique is an adaptation of the Kessner Index. 15 The citing index further includes the month in which the prenatal care begins, for this study, no such discriminated information was available. Tobacco, alcohol, and drug use was considered when the mother had stated that it had been used in any trimester of pregnancy.

Statistical analysis: To describe the study population, we used frequencies, variables with a normal distribution are expressed as mean \pm standard deviation, and variables with a non-normal distribution are expressed as median and interquartile range. Simple logistic regression models were utilized with 95\% confidence intervals, to identify the factors associated with LBW and macrosomia. The factors analyzed were those that are harmful to fetal growth and often occur in pregnancy (infections, hypertension, diabetes, smoking, alcohol and drug use, and maternal malnutrition). Only exposures considered a priori and showing a prevalence of more than $1 \%$ were included in bivariate analyses. Logistic regression models were adjusted by confounder variables: age and maternal schooling. Additionally, it was adjusted per year of birth to show whether it could be a factor influencing exposure and abnormal birth weight. Adjustment variables were defined based on the pattern of association with each exposure and results identified based on literature and exploratory analyses.

Since maternal morbidity could have an impact on the duration of gestation and the number of controls, the potential interactions between these conditions in causing LBW and macrosomia were measured on the logistic regression model. An interaction term for those maternal morbidities that could change the duration of gestation and the number of checks was tested, which were significant were presented in the LBW and macrosomia models.

The data was collected from the universal birth register files, therefore it was not necessary to consider level of significance for the rejection of the null hypothesis. However, a significance level $p=0.05$ was used for the descriptive analysis of the number of births trends per year and birth anthropometry per sex, because it was considered that each subgroup could be a sample of the total period. In the bivariate hypothesis contrast, we performed Pearson's ji-square test for comparing birth ratios by period and by sex. To analyze the differences in anthropometry at birth by sex, the KolmogorovSmirnov normality test was first performed and confirmed that the distribution of the variable birth weight was not normal $(p<0.001)$. Differences in birth anthropometry by sex were calculated using the Wilcoxon Mann-Whitney U-test for independent samples, which reflects the differences in medians of 2 populations when the variable does not have a normal distribution. The data was processed using SPSS Software version 22.

This is a secondary data analysis using data from the government records. We obtained permission to use this data from the area of Epidemiology of the Ministry of Health, with identification of objectives and commitment to use for scientific purposes.

\section{Results}

The numbers of births registered with the SIP between 2009 and 2011 were around 41,000 per year. In 2012 increased by 4,000 newborns, which was $1 \%$ higher, and then these increasing remains. This trajectory change reached statistical significance $(p<0.001)$ compared to the beginning of the series (in 2009-2011).

A total of 303,625 birth data were included in the analysis. The proportion of women who used to be active smokers was one in five, $1 \%$ of mothers had used drugs, and $0.9 \%$ alcohol. $7 \%$ did not meet the minimum number of prenatal care visits for the weeks of gestation. One in 20 women had anemia before 20 weeks and increased to one in 10 in the second half of pregnancy, $6.7 \%$ had hypertensive pregnancy disease, $3.3 \%$ were pre-eclamptic, $12.8 \%$ had at least one episode of bacteriuria. Diabetes Mellitus II and Gestational Diabetes had a frequency of $6.2 \%$. One in 3 women started pregnancy overweight or obese and one in 15 had low pre-gestational weight. The descriptive characteristics of the pregnancies are presented in the Table 1.

The median birth weight was $3,320 \mathrm{~g}$, the length at birth was $49 \mathrm{~cm}$. The inferential analysis found a statistically significant association between the sex of the newborn with weight and length of birth $(p<0.001)$. The proportion of newborns with a birth weight greater than $3,999 \mathrm{~g}$ was $7.3 \%$, and less than $2,500 \mathrm{~g}$ was $6.9 \%$ over the whole period (Table 2 ). In addition, the distributions of LBW and macrosomia 
were significantly different between the sexes $(p<0.001)$.

The prevalence of macrosomia $(>3,999 \mathrm{~g})$ increased since $7.0 \%$ (in 2009) to $8.4 \%$ (in 2015) $(p<0.001)$. The prevalence of LBW $(<2,500 \mathrm{~g})$ decreased since 2012 , standing at $6.6 \%$ in the last year. For both categories of adverse weight at birth, there was a major change between 2011 and 2012 (Figure 1).

The factors that determines more possibilities of LBW were maternal previous pathologies and during pregnancy: preeclampsia $(\mathrm{OR}=4.80 ; \mathrm{CI} 95 \%=4.57$ 5.05), previous hypertension $(\mathrm{OR}=2.11$; $\mathrm{CI} 95 \%=$ 1.96-2.27), hypertensive disease of pregnancy ( $\mathrm{OR}=$ 1.82 ; $\mathrm{CI} 95 \%=1.74-1.90)$. Inadequate control $(\mathrm{OR}=$ 2.29; CI95\%=2.20-2.39), low pre-maternal maternal weight $(\mathrm{OR}=1.65 ; \mathrm{CI} 95 \%=1.58-1.74)$, maternal smoking $(\mathrm{OR}=1.36 ; \mathrm{CI} 95 \%=1.32-1.40)$ and shorter duration of pregnancy $(\mathrm{OR}=2.52$; $\mathrm{CI} 95 \%=$ 2.50-2.55). The results also showed that there are variables that interact with each other. The association between LBW and hypertensive pregnancy disease varies between gestation weeks $(\mathrm{OR}=1.07$; $\mathrm{CI} 95 \%=1.03-1,11)$, the relationship with preeclampsia varies according to weeks of gestation $(\mathrm{OR}=1.05 ; \mathrm{CI} 95 \%=1.01-1.11)$ and the number of controls $(\mathrm{OR}=1.04 ; \mathrm{CI95 \%}=1.01-1.06)$ (Table 3$)$.

Macrosomia was associated with type 1 diabetes
$(\mathrm{OR}=2.21 ; \mathrm{CI} 95 \%=1.86-2.61)$, maternal obesity $(\mathrm{OR}=2.33 ; \mathrm{CI} 95 \%=2.24-2.43)$ and longer gestation $(\mathrm{OR}=2.62 ; \mathrm{CI} 95 \%=2.53-2.72)$ (Table 4$).$ Other factors that predispose a newborn to macrosomia including male sex $(\mathrm{OR}=1.76 ; \mathrm{CI} 95 \%=1.71-1.81)$, diabetes type 2 or Gestational $(\mathrm{OR}=1.78$; CI95\%= 1.70-1.87), pre-gestational overweight $(\mathrm{OR}=1.72$; $\mathrm{CI} 95 \%=1.66-1.78)$, hypertensive pregnancy disease $(\mathrm{OR}=1.08 ; \mathrm{CI} 95 \%=1.03-1.14)$ and it was estimated that for each $\mathrm{cm}$ of maternal size the probability of macrosomia increases $(\mathrm{OR}=1.05$; $\mathrm{CI} 95 \%=$ 1.04-1.05). As for LBW, significant interaction terms were found. The number of controls modifies the effect between the antecedent of the mother of diabetes (type 1, type 2 or gestational) and macrosomia $(\mathrm{OR}=1.10 ;$ CI95\% $=1.03-1.16$ and $\mathrm{OR}=$ 1.11 ; CI95\% $=1.09-1,12$, respectively), the same goes for hypertensive pregnancy disease $(\mathrm{OR}=1.04$; CI95\% $=1.03-1.07)($ Table 4).

\section{Discussion}

Uruguay is characterized by its low fertility rate and low population growth. 16 This study showed higher number of births between 2011 and 2012, however, this increasing did not continue in the period studied. It would also be important to pinpoint the potential problem with pre-2012 SIP files which was non-

\section{Table 1}

Characteristics of mothers and their health conditions in the pregnancy of those born in the 2009-2015 period in Uruguay.

\begin{tabular}{|c|c|c|}
\hline & \multicolumn{2}{|c|}{ Total population } \\
\hline & $\mathbf{N}$ & $\%$ \\
\hline \multicolumn{3}{|l|}{ Education level } \\
\hline Primary and lower & 72.870 & 24.0 \\
\hline Secondary and university & 231.078 & 76.0 \\
\hline Smoking habit & 56.677 & 18.6 \\
\hline Inadequate controls & 20.943 & 6.9 \\
\hline \multicolumn{3}{|l|}{ Anemia } \\
\hline$<20$ weeks & 14.541 & 5.5 \\
\hline$\geq 20$ weeks & 28.082 & 9.3 \\
\hline Preeclampsia & 8.648 & 3.3 \\
\hline Hypertension before pregnancy & 5.903 & 2.2 \\
\hline Hypertensive disease of pregnancy & 20.327 & 6.7 \\
\hline Bacteriuria & 38.822 & 12.8 \\
\hline DMII and DG & 16.435 & 6.2 \\
\hline \multicolumn{3}{|c|}{ Pregestational Nutritional Status $\mathrm{N}=257.501$} \\
\hline Low weight & 16.616 & 6.5 \\
\hline Normal & 158.878 & 61.7 \\
\hline Overweight & 53.818 & 20.9 \\
\hline Obesity & 28.189 & 10.9 \\
\hline
\end{tabular}

DMII= Diabetes Mellitus II; DG= Diabetes Gestacional. 


\begin{tabular}{|c|c|c|c|c|c|c|c|}
\hline & \multicolumn{2}{|c|}{$\begin{array}{l}\text { Total population } \\
\qquad(\mathrm{N}=303.625)\end{array}$} & \multicolumn{2}{|c|}{$\begin{array}{c}\text { Girls } \\
(\mathrm{N}=148.841)\end{array}$} & \multicolumn{2}{|c|}{$\begin{array}{c}\text { Boys } \\
(\mathrm{N}=154.472)\end{array}$} & \multirow[t]{2}{*}{$p$} \\
\hline & \multicolumn{2}{|c|}{ Median (IQR) } & \multicolumn{2}{|c|}{ Median (IQR) } & \multicolumn{2}{|c|}{ Median (IQR) } & \\
\hline Birth weight $(\mathrm{kg})$ & \multicolumn{2}{|c|}{$3.32(3.00-3.63)$} & \multicolumn{2}{|c|}{$3.26(2.95-3.56)$} & \multicolumn{2}{|c|}{$3.37(3.05-3.69)$} & $<0.001 a$ \\
\hline \multirow[t]{2}{*}{ Birth length $(\mathrm{cm})$} & \multicolumn{2}{|c|}{$49.0(47.6-50.3)$} & \multicolumn{2}{|c|}{$49.0(47.5-50.5)$} & \multicolumn{2}{|c|}{$49.5(48.0-51.0)$} & $<0.001 a$ \\
\hline & $\mathrm{N}$ & $\%$ & $\mathrm{~N}$ & $\%$ & $\mathrm{~N}$ & $\%$ & \\
\hline Macrosomia & 22.095 & 7.3 & 8.510 & 5.7 & 14.851 & 9.6 & $<0.001 b$ \\
\hline LBW & 21.106 & 6.9 & 11.101 & 7.5 & 9.917 & 6.4 & $<0.001 b$ \\
\hline
\end{tabular}

LBW= low birth weight; IQR= interquartile range; aU-Mann Whitney Test; bPearson's Chi-square.

Figure 1

Annual prevalence of LBW and macrosomia in the 2009-2015 period in Uruguay.

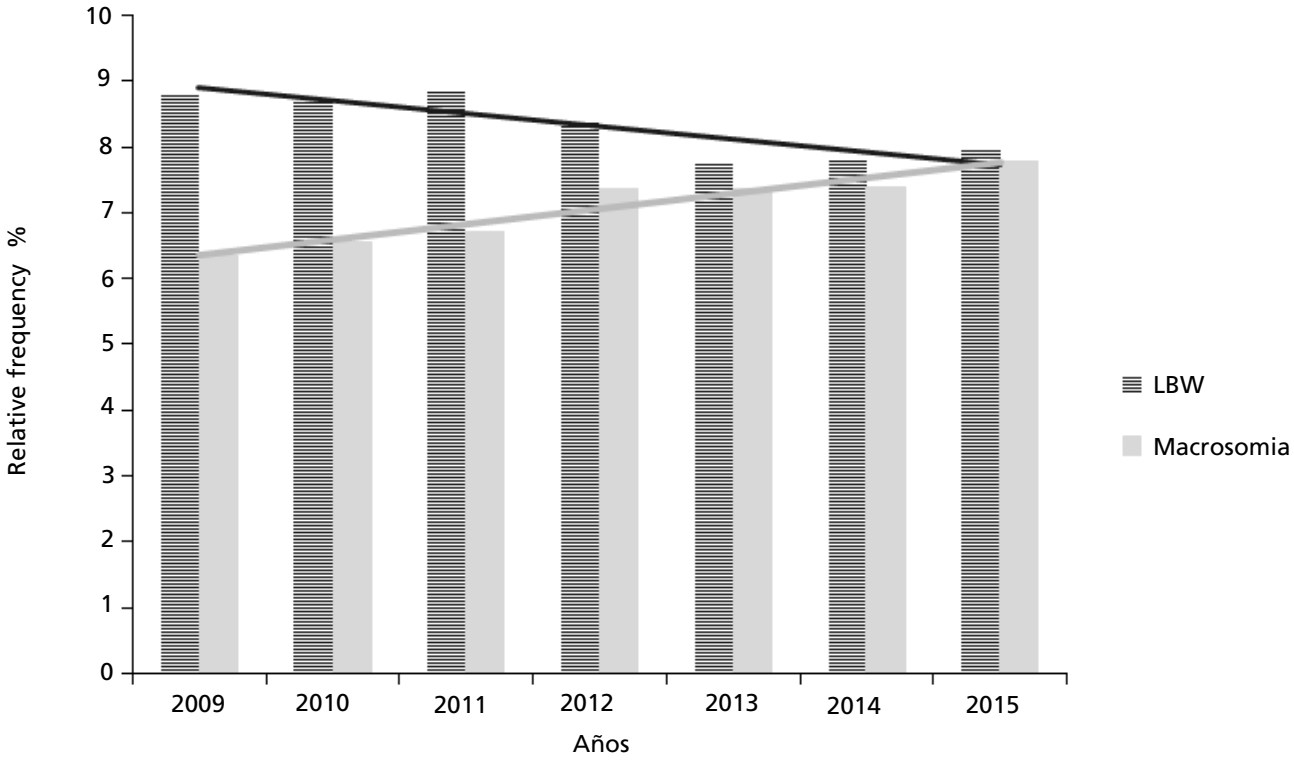

LBW= low birth weigth.

uniformity in data generation between institutions. As a result of this problem is that the Ministry of Health established more stringent regulations for the collection and sending of information. ${ }^{12}$ It is unlikely, however, that such insufficient information will be differential regarding the weight of birth, pregnancy morbidity, lifestyle and social status of pregnant women, therefore the associations we observe are valid.

This study found that in Uruguay the LBW is declining and macrosomia is on the rise. The prevalence of LBW today is lower than previously reported in the country and lower to that observed in Latin America (which put the problem at 9\%), while the prevalence of LBW in other countries in the region have decreased, which is desirable when the short, medium and long-term LBW consequences are known. ${ }^{2}$ Several components that can cause LBW have been recognized and that over time the relative weight of these factors in the problem is changed from technological advances, greater survival of neonates, and changes in the epidemiological profile of the population. 1,17-19 $^{1}$

Complicated hypertension during pregnancy (approximately 9\% worldwide) is usually associated with considerable morbidity and mortality, mainly 
Table 3

Association between maternal characteristics and those of newborns with low birth weight in the period $2009-2015$ in Uruguay $(n=281.853)$

\begin{tabular}{|c|c|c|c|c|c|c|}
\hline & OR crude & $\mathrm{Cl} 95 \%$ & OR adjusted a & $\mathrm{Cl} 95 \%$ & OR adjusted $b$ & $\mathrm{Cl} 95 \%$ \\
\hline \multicolumn{7}{|l|}{ Mothers characteristics } \\
\hline Tobacco use & 1.41 & $1.36-1.46$ & 1.36 & $1.32-1.40$ & 1.36 & $1.32-1.40$ \\
\hline Hypertensive disease of pregnancy (HDP) & 2.16 & $2.05-2.28$ & 1.82 & $1.74-1.90$ & 1.82 & $1.75-1.90$ \\
\hline Preeclampsia & 5.13 & $4.87-5.40$ & 4.80 & 4.57-5.05 & 4.80 & $4.57-5.03$ \\
\hline HTA previa & 2.25 & $2.06-2.46$ & 2.11 & $1.96-2.27$ & 2.11 & $1.96-2.26$ \\
\hline Bacteriuria & 1.08 & $1.03-1.14$ & 1.00 & $0.96-1.04$ & 1.00 & $0.97-1.05$ \\
\hline Inadequate controls & 2.52 & $2.42-2.62$ & 2.29 & $2.20-2.39$ & 2.28 & $2.19-2.37$ \\
\hline Pregnancy consultations $\left(n^{\circ}\right) c$ & 1.30 & $1.29-1.31$ & 1.28 & $1.28-1.29$ & 1.28 & $1.28-1.30$ \\
\hline Low pre-pregnancy maternal weight & 1.63 & $1.55-1.71$ & 1.65 & $1.58-1.74$ & 1.65 & $1.57-1.73$ \\
\hline \multicolumn{7}{|l|}{ Newborns characteristics } \\
\hline Gestation (weeks) c & 2.44 & $2.42-2.50$ & 2.52 & $2.50-2.55$ & 2.50 & $2.50-2.56$ \\
\hline Female & 1.14 & $1.10-1.16$ & 1.19 & $1.16-1.22$ & 1.19 & $1.16-1.22$ \\
\hline \multicolumn{7}{|l|}{ Variable interaction } \\
\hline HDP * pregnancy consultations $\left(n^{\circ}\right) c$ & 1.02 & $1.00-1.03$ & 1.01 & $1.00-1.03$ & 1.01 & $0.99-1.03$ \\
\hline HDP * gestation (weeks) c & 1.07 & $1.03-1.12$ & 1.07 & $1.03-1.11$ & 1.07 & $1.03-1.10$ \\
\hline Preeclampsia * pregnancy consultations $\left(n^{\circ}\right)$ & ) c 1.03 & $1.01-1.05$ & 1.04 & $1.01-1.06$ & 1.04 & $1.01-1.06$ \\
\hline Preeclampsia * gestation (weeks) c & 1.04 & $1.01-1.11$ & 1.05 & $1.01-1.11$ & 1.04 & $1.01-1.11$ \\
\hline
\end{tabular}

$\mathrm{OR}=$ odds ratio; $\mathrm{HDP}=$ hypertensive disease of pregnancy; $\mathrm{HTA}=$ arterial hypertension;

aAdjustment for age and maternal education; bAdjustment for age, maternal education and year of birth; cConverted to 1 / OR for better presentation.

Referencia: Births weighing between $2,500 \mathrm{~g}$ and $4,000 \mathrm{~g}$

Newborns weighing more than $4,000 \mathrm{~g}$ were excluded from this analysis.

\section{Table 4}

Association between maternal characteristics and those of newborns with macrosomia in the period 2009-2015 in Uruguay ( $\mathrm{n}=282.842$ ).

\begin{tabular}{|c|c|c|c|c|c|c|}
\hline & OR crude & $\mathrm{Cl} 195 \%$ & OR adjusted a & $\mathrm{Cl} 195 \%$ & OR adjusted $b$ & $\mathrm{Cl} 195 \%$ \\
\hline \multicolumn{7}{|l|}{ Mothers characteristics } \\
\hline DM I & 2.37 & $2.00-2.81$ & 2.21 & $1.86-2.61$ & 2.20 & $1.86-2.62$ \\
\hline DMII and DG & 1.90 & $1.82-2.00$ & 1.78 & $1.70-1.87$ & 1.78 & $1.70-1.87$ \\
\hline Overweight pregestational & 1.71 & $1.69-1.81$ & 1.72 & $1.66-1.78$ & 1.71 & $1.66-1.77$ \\
\hline Obesidad pregestacional & 2.39 & $2.30-2.48$ & 2.33 & $2.24-2.43$ & 2.32 & $2.23-2.42$ \\
\hline Hypertensive disease of pregnancy (HDP) & 1.12 & $1.06-1.17$ & 1.08 & $1.03-1.14$ & 1.08 & $1.03-1.14$ \\
\hline HTA previa & 1.03 & $0.93-1.13$ & 0.94 & $0.85-1.03$ & 0.94 & $0.85-1.03$ \\
\hline Maternal height (cm) & 1.05 & $1.05-1.06$ & 1.05 & $1.04-1.05$ & 1.05 & $1.04-1.05$ \\
\hline Gestation greater than 40 weeks & 2.54 & $2.45-2.63$ & 2.62 & $2.53-2.72$ & 2.62 & $2.53-2.72$ \\
\hline Primigravity & 1.10 & $1.01-1.19$ & 1.08 & $1.00-1.17$ & 1.10 & $1.00-1.19$ \\
\hline \multicolumn{7}{|l|}{ Newborn characteristics } \\
\hline Male & 1.74 & $1.69-1.79$ & 1.76 & $1.71-1.81$ & 1.76 & $1.71-1.81$ \\
\hline \multicolumn{7}{|l|}{ Variable interaction } \\
\hline DMI * pregnancy consultations $\left(n^{\circ}\right) c$ & 1.10 & $1.03-1.16$ & 1.10 & $1.03-1.16$ & 1.09 & $1.03-1.16$ \\
\hline DMII and DG * pregnancy consultations $\left(n^{\circ}\right) c$ & c 1.11 & $1.09-1.12$ & 1.11 & $1.09-1.12$ & 1.11 & $1.08-1.12$ \\
\hline HDP * pregnancy consultations $\left(n^{\circ}\right) c$ & 1.05 & $1.03-1.07$ & 1.04 & $1.03-1.07$ & 1.05 & $1.02-1.07$ \\
\hline
\end{tabular}

$\mathrm{OR}=$ odds ratio; $\mathrm{HDP}=$ hypertensive disease of pregnancy; HTA= arterial hypertension; DMI= diabetes mellitus 1 ; DMII: diabetes mellitus 2 ; $\mathrm{DG}=$ diabetes gestacional; a Adjustment for age and maternal education; b Adjustment for age, maternal education and year of birth; cConverted to 1 / OR for better presentation.

Referencia: Births weighing between $2,500 \mathrm{~g}$ and 4,000g.

Newborns weighing less than $2,500 \mathrm{~g}$ were excluded from this analysis. 
due to preeclampsia. 20 Other analyses of the impact of gestational hypertension showed that not only impacts the newborn's situation, since the systematic review by Davis and colleagues concluded that the offspring of women with preeclampsia showed higher blood pressure and BMI during early childhood and adulthood compared to those whose mothers had not developed disease. ${ }^{21}$

This study therefore indicates the benefits or advantages from the number of controls during pregnancy that are programmed to evaluate the course of gestation and possibly detect abnormalities and alterations in the growth of the fetus during intrauterine development and maternal problems or pathologies. A study in western China showed that at least five controls during pregnancy were associated with decreased in LBW, in the same study at least eight controls showed a greater reduction. ${ }^{11}$ Another study, conducted in Brazil showed that at least seven visits were protective of LBW. 22

Low maternal weight is an indicator of pregestational malnutrition, which can predispose for intrauterine malnutrition, visualized in the LBW. This association has also been demonstrated by a systematic review of 12 longitudinal studies. 23

Understanding the factors associated with LBW would help make effective health interventions in women before and during pregnancy. In addition, the analysis of variables interacting in their association with LBW indicates that the effects found in the exposures vary by week of gestation and number of controls. The results show that for the effectiveness of intervention approaches, they should include: pregnancy planning (for women to start with good nutritional status, health, and wellbeing), regular contact with health equipment, and early detection of the threat of preterm birth, or any risk that determines preterm birth. ${ }^{24}$ The evidence also supports social determinants which set women most vulnerable and for which community-based interventions would be necessary. 25 The results of the effects of tobacco emphasizes the need for actions against maternal and fetal exposure to tobacco smoke to eliminate the harm this exposure demonstrates. ${ }^{26}$

This study found that macrosomia in newborns was prevalent, especially in male neonates, becoming an increasingly common problem. Macrosomia has been associated with increased risk of cesarean delivery, fetal dystocia with clavicular and brachial plexus lesions, and a wide range of health problems later in life, such as childhood obesity, being the latter a risk factor for adult obesity and noncommunicable diseases. 27

This study showed a direct and positive associa- tion between maternal excess malnutrition at the beginning of pregnancy and macrosomia. It was also shown, as well as previous publications, that women with diabetes (Diabetes Mellitus Type I/II and Gestational Diabetes) have a higher chance of fetal macrosomia and this association increases as controls decrease. Additionally, cohort studies have provided evidence suggesting that the intrauterine environment has a long-lasting impact on the child's adiposity of the offspring. ${ }^{28-30}$ Therefore, the nutritional and metabolic status of the mother can have adverse effects on the body size of the newborn, since it can heighten the risk of transgenerational effects on obesity in her offspring.

Our study is not without limitations. All pregestational data were self-reported. While analyzing national data provides useful information to understand reality and to recommend public health strategies, according to the data available to carry out this study, some unresolved issues remain. The association of pre-pregnancy nutritional status with abnormal birth weight is clear, however, what happens to weight gain or nutritional status at the end of pregnancy could not be analyzed. These data are present on the pregnant woman's health records card but are not lifted by the SIP, it would be important to systematize all data.

Our study has several strengths. It is populationbased and included all the country's births for six years and includes populations of all socioeconomic strata, regions, cities, towns, and rural areas of the country, which allowed us to properly quantify the direct and indirect effects and approach national reality.

In short, this study showed that the weight of newborns is influenced by noncommunicable diseases and pre-pregnancy nutritional status. Potentially, the prevalence of LBW and macrosomia could be modified with adequate pregnancy planning and health control. The way to successfully address this problem would be to universalize health care assistance during pregnancy, therefore ensuring pregnant women the right of trusted and qualified care during gestation, focusing on a reduction in LBW and macrosomia rates.

\section{Author's contribution}

Pereyra I designed the study, performed the literature review, analyzed the data and wrote the manuscript. Bustos P assisted in the interpretation of the data and participated in the writing and editing of the manuscript. All authors approved the final version of the article. 


\section{References}

1. Uruguay. Ministerio de Salud. Objetivos Sanitarios Nacionales 2020 - Hacia un abordaje integral. Montevideo; 2016.

2. UNICEF. Estado mundial de la infancia 2016. 2016. 1-173 $\mathrm{p}$.

3. WHO (World Health Organization). Low Birth Weight Wold Health Organization; 2014. https://www.who.int/ nutrition/publications/globaltargets2025_policybrief_lbw/e $\mathrm{n} /$ (accedido el 09/Ago/2019)

4. Banco Mundial. Bebés con bajo peso al nacer $(\%$ de nacimientos)| Data [Internet]. [accedido el 30/Ene/2020]. Available from: https://datos.bancomundial.org/ indicador/SH.STA.BRTW.ZS

5. Heidari-Beni M. Early Life Nutrition and Non Communicable Disease. Adv Exp Med Biol. 2019; 1121: $33-40$

6. Eriksson JG. Developmental Origins of Health and Disease - from a small body size at birth to epigenetics. Ann Med. 2016; 48 (6): 456-67.

7. Eriksson JG. Early growth and coronary heart disease and type 2 diabetes: findings from the Helsinki Birth Cohort Study (HBCS). Am J Clin Nutr. 2011; 94 (6_Suppl.): 1799S-1802S

8. Koyanagi A, Zhang J, Dagvadorj A, Hirayama F, Shibuya $\mathrm{K}$, Souza JP, et al. Macrosomia in 23 developing countries: An analysis of a multicountry, facility-based, crosssectional survey. Lancet. 2013; 381: 476-83.

9. Goosby BJ, Cheadle JE, McDade T. Birth weight, early life course BMI, and body size change: Chains of risk to adult inflammation? Soc Sci Med. 2016; 148: 102-9.

10. Kang M, Yoo JE, Kim K, Choi S, Park SM. Associations between birth weight, obesity, fat mass and lean mass in Korean adolescents: The Fifth Korea National Health and Nutrition Examination Survey. BMJ Open. 2018; 8 (2): 1-9.

11. Uruguay. Ministerio de Salud Pública. Presentación sobre natalidad, fecundidad y mortalidad infantil en Uruguay 2018. Ministerio de Salud Pública, Uruguay; 2018. [accedido el 09 Ago 2019]. https://www.gub.uy/ministerio-saludpublica/comunicacion/publicaciones/presentacion-sobrenatalidad-fecundidad-y-mortalidad-infantil-en-uruguay

12. Uruguay. Ministerio de Salud Pública. Actualización del Sistema Informático Perinatal, llenado del mismo y datos institucionales [Internet]. Uruguay; 2012 p. 57-77. [accedido el 30/Ene/2020]. Available from: https://www.gub.uy/ ministerio-salud-publica/sites/ministerio-salud-publica/ files/2018-09/Comunicado MSP - 2012 A instituciones de salud sobre llenado hoja SIP.pdf

13. Henriques LB, Alves EB, Vieira FMDSB, Cardoso BB, D'Angeles ACR, Cruz OG, et al. Acurácia da determinação da idade gestacional no Sistema de Informações sobre Nascidos Vivos (SINASC): um estudo de base populacional. Cad Saúde Pública. 2019; 35 (3): e00098918-27.

14. WHO (World Health Organization). Body mass index BMI. World Health Organization; 2018. [accedido el 09 Ago 2019]. http://www.euro.who.int/en/healthtopics/disease-prevention/nutrition/a-healthylifestyle/body-mass-index-bmi
15. Kotelchuck M. An evaluation of the Kessner Adequacy of Prenatal Care Index and a proposed Adequacy of Prenatal Care Utilization Index. Am J Public Health. 1994; 84 (9): 1414-20.

16. Batthyany K, Genta N. Tendencias demográficas de la población uruguaya [Internet]. Montevideo; 2016. [accedido el 30 Ene 2020]. Available from: https://www.opp.gub.uy/sites/default/files/inlinefiles/Genero_demografia.pdf

17. Bian Y, Zhang Z, Liu Q, Wu D, Wang S. Maternal risk factors for low birth weight for term births in a developed region in China: A hospital-based study of 55,633 pregnancies. J Biomed Res. 2013; 27 (1): 14-22.

18. Restrepo Mesa SL, Parra Sosa BE. Implicaciones del estado nutricional materno en el peso al nacer del neonato. Perspect Nutr Hum. 2009; 11 (2): 179-86.

19. Villar J, Carroli G, Wojdyla D, Giordano D, Bergsjø P, Bakketeig L, et al. Preeclampsia, gestational hypertension and intrauterine growth restriction, related or independent conditions ? Am J Obstet Gynecol. 2006; 194: 921-31.

20. Davis EF, Lazdam M, Lewandowski AJ, Worton SA, Kelly B, Kenworthy Y, Adwani S Wilkinson AR, McCormick K, Sargent I, Redman C, Leeson P. Cardiovascular risk factors in children and young adults born to preeclamptic pregnancies: A systematic review. Pediatrics. 2012; 129 (6): e155261

21. Zhou H, Wang A, Huang X, Guo S, Yang Y, Martin K, et al. Quality antenatal care protects against low birth weight in 42 poor counties of Western China. PLoS One. 2019; 14 (1): $1-14$.

22. Branco da Fonseca R, Louzada M, de Carvalho L, Fiorini R. Adequacy of antenatal care and its relationship with low birth weight in Botucatu, São Paulo , Brazil : a case-control study. BMC Pregnancy Childbirth. 2014; 14: 255-67.

23. Tang A, Dong K, Deitchler M, Chung M, MaaloufManasseh Z, Tumilowicz A, Wanke C. Use of Cutoffs for Mid-Upper Arm Circumference (MUAC) as an Indicator or Predictor of Nutritional and Health- Related Outcomes in Adolescents and Adults: A Systematic Review. Washington DC: Food and Nutrition Technical Assistance III Project (FANTA); 2013. Available from: https://www.fantaproject.org/sites/default/files/resources/MUAC\%20Systematic \%20Review\%20_Nov\%2019.pdf

24. Institute of Medicine. Weight Gain During Pregnancy: Reexamining the Guidelines. Washington DC; 2009. [accedido el 09 Ago 2019]. Available from: https://www.nap.edu/catalog/12584/weight-gain-duringpregnancy-reexamining-the-guidelines

25. Kim D, Saada A. The Social Determinants of Infant Mortality and Birth Outcomes in Western Developed Nations : A Cross-Country Systematic Review. Int J Env Res Public Heal. 2013; 10: 2296-335.

26. Ward C, Lewis S, Coleman T. Prevalence of maternal smoking and environmental tobacco smoke retrospective study using Millennium Cohort. BiMC Public Heal. 2007; 7 (81): 1-7.

27. Zhang X, Decker A, Platt RW, Kramer MS. How big is too 
big? The perinatal consequences of fetal macrosomia. Am J Obstet Gynecol. 2008; 198 (5): 517.e1-517.e6.

28. Yu Z, Han S, Zhu J, Sun X, Ji C, Guo X. Pre-Pregnancy Body Mass Index in Relation to Infant Birth Weight and Offspring Overweight / Obesity : A Systematic Review and Meta-Analysis. PLoS One. 2013; 8 (4): e61627.

29. Adane AA, Tooth LR, Mishra GD. The role of offspring's birthweight on the association between pre-pregnancy obesity and offspring's childhood anthropometrics : a mediation analysis. J Dev Orig Health Dis. 2019; 10 (5): 570-7.
30. Nehring I, Chmitorz A, Reulen H, von Kries R, Ensenauer $\mathrm{R}$. Gestational diabetes predicts the risk of childhood overweight and abdominal circumference independent of maternal obesity. Diabet Med. 2013; 30 (12): 1449-56.

Received on November 15, 2019

Final version presented on June 4, 2020

Approved on June 30, 2020 